Horizons philosophiques

\title{
Citéphilo 98 : Penser ensemble. Présentation
}

\section{Ghyslaine Guertin}

Volume 9, numéro 2, printemps 1999

La philosophie à portée de voix

URI : https://id.erudit.org/iderudit/801128ar

DOI : https://doi.org/10.7202/801128ar

Aller au sommaire du numéro

\section{Éditeur(s)}

Collège Édouard-Montpetit

\section{ISSN}

1181-9227 (imprimé)

1920-2954 (numérique)

Découvrir la revue

\section{Citer ce document}

Guertin, G. (1999). Citéphilo 98 : Penser ensemble. Présentation. Horizons philosophiques, 9(2), 77-77. https://doi.org/10.7202/801128ar d'utilisation que vous pouvez consulter en ligne.

https://apropos.erudit.org/fr/usagers/politique-dutilisation/ 


\section{CITÉPHILO 98 : PENSER ENSEMBLE}

Cette deuxième édition de Citéphilo proposait, comme la première, de Penser ensemble, reprenant ainsi à son compte la question que posait Kant : «...penserions-nous beaucoup et penserions-nous bien, si nous ne pensions pour ainsi dire avec les autres?»

Pour une deuxième année consécutive ${ }^{1}$, des étudiants du Collège Édouard-Montpetit participaient en novembre dernier à la seconde Semaine européenne de la philosophie, en France, à Lille². Ce premier contact avec l'Europe et sa diversité des cultures, leur a permis d'élargir leur vision du monde, de confronter leur manière de penser et leur quête de sens avec un public animé par cette "nouvelle" passion pour la philosophie.

Nous les avons invités à communiquer leur expérience. Ils ont choisi la forme du compte rendu pour illustrer l'intérêt et l'enthousiasme qui les ont habités lors d'un entretien, d'une conférence ou d'un débat présentés dans le cadre du programme.

\section{Ghyslaine Guertin}

1. Voir le compte rendu de la participation de nos étudiants à Citéphilo 97 dans Horizons philosophiques, "Besoin de philosophie", pp. 117-122, vol.8 no 2.

2. Ces mêmes étudiants ont également pris part, dans le cadre de cette Semaine européenne de la philosophie, a un échange franco-québécois avec les étudiants de Lille. Ensemble, reliés à une cinquantaine de jeunes par visioconférence au Collège Édouard-Montpetit et à Lille, ils ont participé à un débat à partir de la question "Que peut-on attendre de la philosophie?"

II convient de remercier les organisateurs de Citéphilo, Gilbert Glasman, Marcel Saint-Paul et Léon Wiznia ainsi que les autres collaborateurs qui ont soutenu l'ensemble du projet : Les Ministère de l'Éducation et des Relations internationales du gouvernement du Québec; L'Office franco-québécois pour la jeunesse (OFQJ); La Direction des études du Collège Edouard-Montpetit; Pierre Brazé, adjoint à la directrice des études; Jacques Drolet, réalisateur; Michel Caron, régisseur. La Direction des Services aux étudiants et l'Association des parents du Collège Édouard-Montpetit. Nous tenons également à exprimer notre reconnaissance à Jean-Raymond Degrève, adjoint au Maire, Mairie de Lille; Jean-Paul Bougeard et Luc Hossepied, de Canal 9, T.V. sur le cable, Lille. 